\title{
Composition distribution and characteristic of a typical commercial gasoline in market
}

\author{
Li Na*, Guo Xin, Tao Zhiping, Long Jun \\ Research Institute of Petroleum Processing, Beijing, China
}

\begin{abstract}
Composition distribution of a typical commercial gasoline more representative in current market which also meets China V gasoline standard is discussed. The octane number distribution and vapor pressure distribution of the commercial gasoline is also analyzed. In addition, the hydrocarbon making a larger contribution to the octane number or vapor pressure is reached. The results indicate that the commercial gasoline more representative in the current market mainly includes i-paraffin, aromatics and a small amount of olefins in order to meet the China $\mathrm{V}$ gasoline standard. Olefin is the main composition which contributes to the octane number and vapor pressure for the light fraction of commercial gasoline. However, in order to meet the $\mathrm{V}$ gasoline standards, the olefin content decreases so greatly that we have to add a certain amount of MTBE to make up for the octane value loss and vapor pressure loss of the commercial gasoline. Aromatics are the components that contribute to the octane number for heavy fraction of commercial gasoline. However, the octane number of the middle distillate is relatively absent. In order to satisfy the good combustion performance of commercial gasoline, it is very important to improve the distribution of octane number by adjusting the gasoline component.
\end{abstract}

Keywords: Gasoline, composition, octane number, boiling range, vapor pressure, distribution, quality upgrade

\section{Introduction}

In recent years, global automobile holdings continue to increase which play a huge role to promote economic development and the level of human life. However, the problem of air pollution caused by vehicle is becoming increasingly serious, thus a large number of pollutants emissions into the atmosphere, which threats to human health every year. In order to protect the environment, the world's countries carry out strict restrictions on vehicle emissions. To this end, the petrochemical industry is also aimed at the quality of fuel for continuous quality upgrade [1].

Unburned or incomplete combustion of fuel is the main cause of engine emissions [2]. Therefore, composition and properties distribution of fuel has a significant impact inevitably on emissions of harmful pollutants and the number of species [3], [4]. With the increasing development of environmental protection and engine technology, it is necessary to make a thorough study on the distribution characteristic of the representative commercial gasoline in the market at present, such as the distribution of the composition and octane number, vapor pressure and so on. It is urgent to make a more reasonable adjustment and control of the composition of gasoline, so that it is more adaptive to the continuous improvement of engine technology [5], [6].

At present, it is quite common to study on the composition and properties of gasoline blending components. However, the composition and characteristics of the typical commercial gasoline have not been reported. So the composition and characteristics of typical commercial gasoline in the market are deeply discussed. It has important directive significance to grasp the link between main criteria and composition of gasoline, adjust the main components of gasoline standard according to the current oil

\footnotetext{
${ }^{*}$ Manuscript received April 14, 2016; revised July 30, 2016.

Corresponding author. Tel.: +010-82368079; E-mail address: linabeiruoyi@163.com

doi: $10.12720 /$ sgce $.5 .3 .182-187$
} 
situation and the composition of commercial gasoline in our country for guiding the further improvement of the quality of gasoline.

\section{Experimental}

\subsection{Materials}

The gasoline sample used in this study is a typical commercial gasoline in the market which meets the country's V gasoline standard.

\subsection{Measurement}

Gasoline monomer hydrocarbon analysis (PONA analysis, Analysis of Paraffin Olefin Naphthenic Aromatic) is a method for qualitative and quantitative analysis of monomer hydrocarbons in gasoline by using high resolution non polar capillary column and hydrogen flame ionization detector.

According to the individual hydrocarbons in gasoline data, composition of gasoline can be understood from the molecular structure. Moreover, we can further understand the test sample of oil monomer hydrocarbon distribution, vapor pressure distribution and octane number distribution according to the boiling point, octane number, vapor pressure and other basic data.

\subsection{Method}

The relationship between the composition characteristics of commercial gasoline and the properties of octane number, boiling point and vapor pressure can be directly expressed by means of three-dimensional graphic model. Therefore, first of all, hydrocarbon monomers composition of the commercial gasoline is analyzed. $\mathrm{X}$ axis at boiling point $/{ }^{\circ} \mathrm{C}, \mathrm{Y}$ axis at Hydrocarbon group $(1$ on behalf of alkanes and cycloalkanes, 2 on behalf of i-paraffin, 3 representatives for olefins, 4 on behalf of aromatic hydrocarbons, 5 representatives of MTBE; the same below), and

1) the mass fraction of each monomer hydrocarbon $\omega / \%$ for the $Z$ axis as the three-dimensional map image to express the composition distribution of gasoline components. Fig. 1.

2) the mass fraction of each monomer hydrocarbon $\omega / \%$ multiples research octane number (RON) or motor octane number (MON) which corresponds to the single hydrocarbon, thus $\omega \times \mathrm{RON}$ and $\omega \times \mathrm{MON}$, for the $\mathrm{Z}$ axis as the three-dimensional map image to express the octane number distribution of the commercial gasoline. Fig. 2-Fig. 3.

3 ) the mass fraction of each monomer hydrocarbon $\omega / \%$ multiples the corresponding vapor pressure, thus $\omega \times \mathrm{VP}$ for the $\mathrm{Z}$ axis as the three-dimensional map image to express the vapor pressure distribution of gasoline components. Fig. 4.

\section{Results and Discussion}

\subsection{Composition distribution}

The composition characteristics of the typical commercial gasoline can be expressed intuitively through the three-dimensional model image, see Fig. 1. It can be directly seen that the boiling range, hydrocarbon type and the general content of the monomer hydrocarbon contained in it. That is, the C5 C7 i-paraffin whose boiling point is around 30 90 ${ }^{\circ} \mathrm{C}, \mathrm{C} 7 \sim \mathrm{C} 9$ aromatic hydrocarbons (boiling point of $110 \sim 160^{\circ} \mathrm{C}$ ) accounted for a large proportion. Moreover, The proportion of C5 C7 olefins whose boiling point is $40 \sim 90^{\circ} \mathrm{C}$ is also relatively large. At the same time, in order to ensure that the gasoline to meet a certain octane value, methyl tertiary butyl ether additive(boiling point is about $55^{\circ} \mathrm{C}$ ), which accounts for about $10 \%$ of the total.

It can be concluded that, reducing olefin content, at the same time in order to ensure a certain octane number and a suitable vapor pressure, we have to add a high octane value additive MTBE to the commercial gasoline, in order to meet the national $\mathrm{V}$ gasoline standards 
In addition, by analyzing the boiling range, thus the distribution of distillation range, It can be known that the main components below $\mathrm{T} 10$ are as follows, $\mathrm{C} 4 \sim \mathrm{C} 5$ alkanes, isomeric alkanes, alkenes and a part of C6 isomers. A distillation between T10 T50 components are mainly C6 C7 alkanes, cycloalkanes, isomeric alkanes and alkenes. A distillation between T50 T90 components are mainly C7 C8 and part of C9 aromatic hydrocarbons, C8 C9 alkanes, cycloalkanes and i-paraffin. After T90, are mainly C9 or more heavy aromatics. It is very important to analysis every typical distillate segments of commercial gasoline for adjustment of finished gasoline boiling range distribution and gasoline composition more effectively.

At the same time, heavy aromatics content is higher, and heavy aromatics are important factor of influence on engine emissions [7], [8]. In order to reduce emissions, a reasonable adjustment according to the composition characteristics of commercial gasoline is necessary to meet the higher requirements of environmental protection goals.

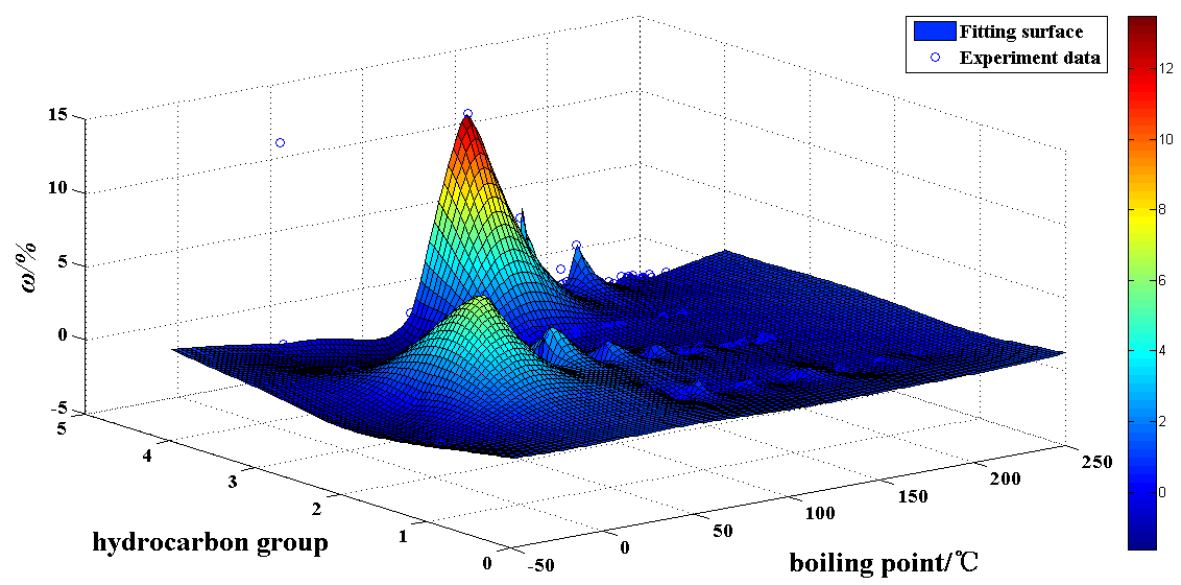

Fig. 1. Composition distribution of the commercial gasoline.

\subsection{Octane number distribution}

The octane number of gasoline depends to a great extent on its hydrocarbon composition, which is closely related to the molecular structure and the number of carbon atoms in the molecule (relative molecular mass). It is very known that octane number in turn, when the relative molecular mass is approximately the same: aromatic hydrocarbon> isomerization alkane and i-alkenes>n-alkenes and cycloalkanes > n-alkanes [9].

The octane number distribution of the typical commercial gasoline can be expressed intuitively through the three-dimensional model image, as shown in Fig. $2 \sim$ Fig. 3.

It can be indicated that research octane number distribution and motor octane number distribution is very consistent.

C5and C9 i-alkanes whose boiling point is respectively around $30^{\circ} \mathrm{C}$ and $90^{\circ} \mathrm{C}, \mathrm{C} 5$ olefins boiling point about $40^{\circ} \mathrm{C}, \mathrm{C} 7 \sim \mathrm{C} 9$ aromatic hydrocarbons whose boiling point is $110 \sim 170^{\circ} \mathrm{C}$, mainly provide octane number. Meanwhile, MTBE accounted for a larger proportion to octane value. In addition, it is can be concluded that C5 alkanes and C5 olefins and MTBE mainly provide octane value below T10. T10 T50 is mainly composed of $\mathrm{C} 6 \sim \mathrm{C} 7 \mathrm{i}$-alkanes and olefins with boiling point $60 \sim 90{ }^{\circ} \mathrm{C}$. Octane number of T50 T90 fraction is mainly provided by $\mathrm{C} 7 \sim \mathrm{C} 8$ aromatics with boiling point $110 \sim 140^{\circ} \mathrm{C}$ and above $\mathrm{T} 90$ is major of $\mathrm{C} 9$ aromatics (about $\left.170^{\circ} \mathrm{C}\right)$.

Further, if we continue to reduce the olefin content in gasoline, the octane number of the fraction below T10 will reduce significantly. In this case, octane number of the light fraction cannot be guaranteed. And by analyzing the octane number distribution of commercial gasoline, before the proportion of the 
alkylation gasoline is not improved, aromatic hydrocarbon (reforming gasoline) and MTBE mainly provide octane number at present in order to meet the olefin content in the national V standard [10].

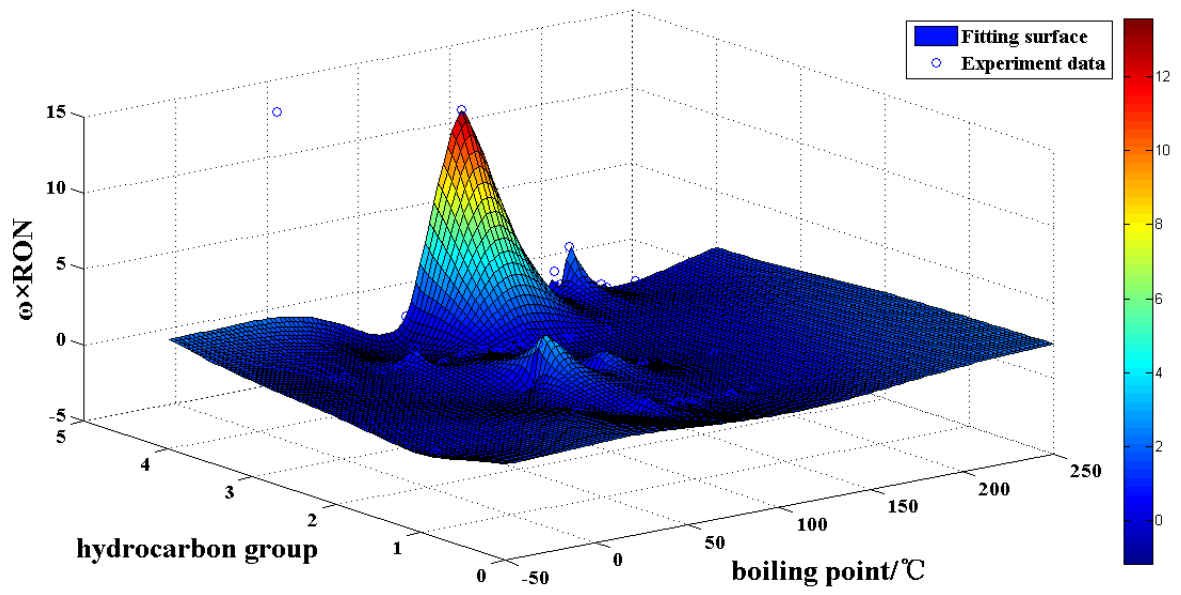

Fig. 2. RON distribution of the commercial gasoline.

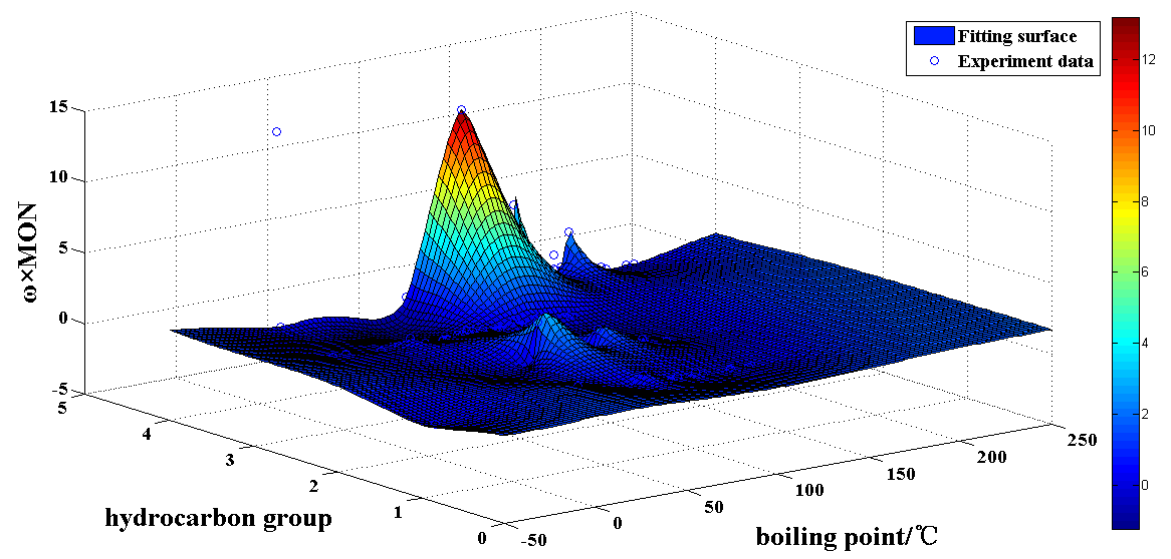

Fig. 3. MON distribution of the commercial gasoline.

\subsection{Vapor pressure distribution}

Vapor pressure is often used to describe the volatility of gasoline. Gasoline volatility is affected by various factors, generally lighter the gasoline components, better the volatile; more light alkanes, better volatile; more heavy aromatics, the worse volatile; more heavy olefins, volatile in the middle. The evaporation emission and the starting performance of the vehicle have important relation with the vapor pressure of gasoline [11], [12]. Due to air resistance, the gasoline vapor pressure should be strictly controlled at high temperature; at low temperature, the gasoline needs to have a higher vapor pressure. Only in this way does engine have a good startup performance. So with the change of seasons, gasoline vapor pressure requirements should change correspondingly.

The vapor pressure distribution of the typical commercial gasoline can be expressed intuitively through the three-dimensional model image, as shown in Fig. 4. For the commercial gasoline, the vapor pressure is mainly provided by the distillation below T10, mainly for the C4 C5 n-alkanes, i-alkanes and olefins, as well as part of the C6 i-alkanes. Thus, in order to improve vapor pressure of the commercial gasoline, the light fraction whose boiling point lower than T10 should be added to the gasoline, at the same time it should be noted that the T10 should meet the requirements of national V gasoline standard. 


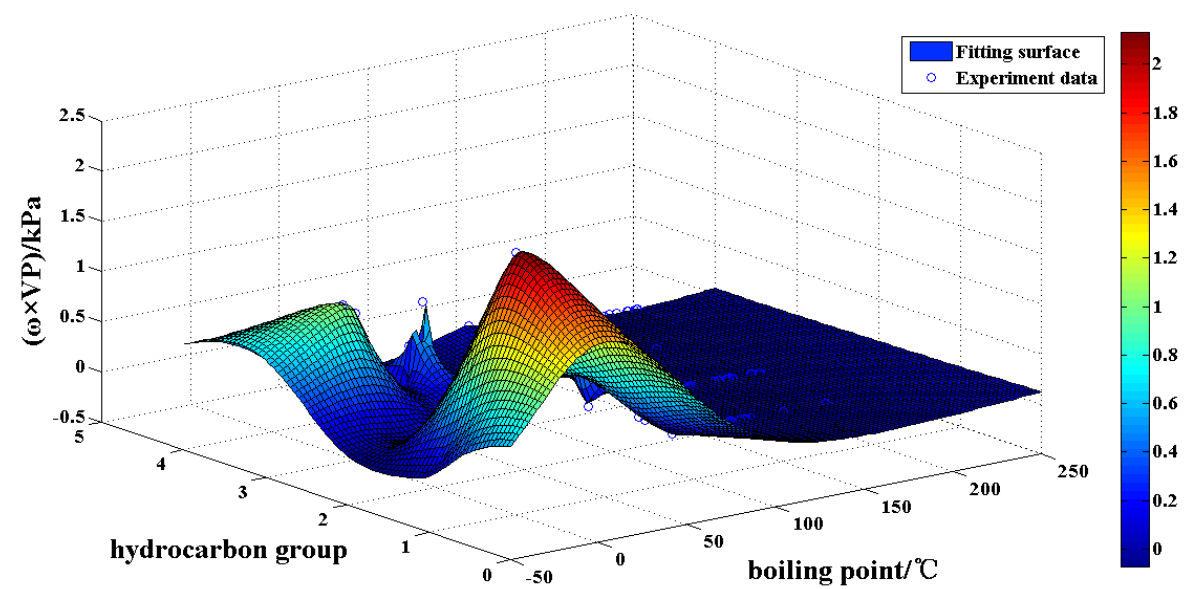

Fig. 4. Vapor pressure distribution of the commercial gasoline.

\section{Summary}

Through the comparative analysis of the monomer hydrocarbon of the commercial gasoline which is representative to meet national $\mathrm{V}$ standard in market, it is concluded that the composition distribution, the octane number distribution, the vapor pressure distribution, and which composition mainly contributes to the octane number and the vapor pressure. Olefin is an important component in the provision for the octane number of the light fraction and vapor pressure of the commercial gasoline. If we continue to reduce the olefin content in the gasoline quality upgrading, the octane number and vapor pressure of light cannot be guaranteed. With the alkylation process not been large-scale industrialization, the high octane number additive MTBE has to been added to the gasoline in order to ensure that the octane number of gasoline. But MTBE is harmful to the human body, higher cost, it is not the long run to use MTBE to make up octane number and vapor pressure in long term. We should devote great efforts to the development of these clean gasoline production technology, in order to meet China's increasingly stringent environmental requirements and the needs of the engines.

\section{Acknowledgement}

The authors wish to thank Qian Hengxiao and Luo Hu for their technical expertise and commitment to this project.

\section{References}

[1] Guo X. The development of gasoline standards and emission regulations and the trend of clean gasoline production technology in China. Petroleum Products Application Research, 2012; 6(3):5-13

[2] Jain AK, Singh SP, Pathak S, et al. Effect of improving the gasoline fuel quality on exhaust emissions from in-use vehiclesan experimental study. In: Proc. of SIAT, 2009.

[3] Kanehara K, Sasajima N, Nakada M, et al. Analyzing the influence of gasoline characteristics on transient engine performance. In: Proc. of International Fuels \& Lubricants Meeting \& Exposition, 1991.

[4] Sugaware Y, Akasaka Y, Kagami M. Effect of gasoline properties on acceleration performance of commercial vehicles. In: Proc. of SAE, 1997.

[5] Reed H, Derek S, Rolf R. Operating a heavy-duty direct-injection compression-ignition engine with gasoline for low emissions. SAE, 2009.

[6] Vaughn RB, Albert MH, Robert MR, et al. Gasoline reformulation and vehicle technology effects on emissions-auto. SAE.

[7] Diana S, Giglio V, Iorio B, et al. The influence of fuel composition on pollutant emission of premixed spark ignition engines in presence of EGR. In: Proc. of International Fall Fuels and Lubricants Meeting and Exposition, 1998. 
[8] Wedekind B, Bennett PJ. The independent effect of mid-range, back-end volatility and aromatics on emissions from two European gasoline engines. In: Proc. of SAE International Fall Fuels and Lubricants Meeting and Exhibition, 1995.

[9] Peng P, Lu W. The relationship between octane number and composition of gasoline. Petroleum Processing and Petrochemicals, 1981; 6:27-38.

[10] Guo X. Status analysis and development suggestion of gasoline quality upgrading in China. Petroleum Products Application Research, 2013; 6(3):4-11.

[11] Shibata Y, Omata T, Hayashi A, et al. Result of JCAP I studies and outline of JCAP II program. In: Proc. of SAE, 2003.

[12] Koseki K, Matsumoto T, Morita K. RVP dependence of evaporative emissions for japanese current and older vehicles and U.S. vehicles using typical Japanese Gasoline. In: Proc. of SAE, 2000. 